\title{
Formative feedback on a patient-based assessment: comparing student perceptions of two feedback methods
}

\author{
Marygrace Elson, MD, MME, ${ }^{1}$ and Rick D. Axelson, $\mathrm{PhD}^{2}$ \\ Key words: education, medical; educational measurement; delayed feedback; formative \\ feedback; patient-based assessment
}

\begin{abstract}
:
Introduction: Although formative feedback is widely recognized as an essential aid to student learning, there is little evidence regarding effective ways of providing formative feedback on structured clinical exams. This study compares students' perceptions of immediate, face-to-face feedback with delayed, written on-line faculty feedback on their Obstetrics and Gynecology medical student clerkship patient-based assessment (PBA) at the University of lowa.

Methods: Between October 2009-2010, 163 third year medical students performed the PBA. Students were assigned to immediate face-to-face or delayed, written on-line feedback. One week after completion of all feedback, students were invited to participate in an anonymous web-based survey. Independent samples t-tests were used to determine whether the mean differences between the groups in ratings of commonly accepted characteristics of effective feedback were statistically significant.
\end{abstract}

Results: A total of 97 students responded to the survey. Of the 84 who responded to the questions about feedback quality (face-toface feedback $n=40$, web-based feedback $n=44)$, face-to-face feedback generally scored higher than web-based feedback, and received significantly higher ratings in 9 of 11 variables measured ( $p \leq 0.05)$. Qualitative comments indicated preference for two-way interaction with evaluators.

Conclusion: Students rate immediate faceto-face feedback more beneficial than delayed, web-based written feedback on a patient-based assessment.

${ }^{1}$ The Department of Obstetrics and Gynecology, Roy J. and Lucille A. Carver College of Medicine, The University of lowa, lowa City, lowa, USA. ${ }^{2}$ Office for Consultation and Research in Medical Education, Roy J. and Lucille A. Carver College of Medicine, The University of lowa, lowa City, IA.

\section{Introduction}

Relatively few studies have examined the most effective way to provide formative feedback on a structured clinical exam. Although it is generally held that immediate, direct feedback on clinical performance is best, ${ }^{1,2}$ the studies supporting this finding examine simple clinical skills and, thus, may not be directly applicable to the structured clinical exam.

Please cite this paper as: Elson M, Axelson RD. Formative feedback on a patient-based assessment: comparing student perceptions of two feedback methods. Proc Obstet Gynecol. 2012 May 2(3):Article 1 [ 6 p.]. Available from: http://ir.uiowa.edu/pog/. Free full text article.

Corresponding author: Marygrace Elson, MD, MME, Department of Obstetrics and Gynecology, University of lowa, 51230 PFP, 200 Hawkins Drive, lowa City, IA 52242. Telephone (319)356-3053. marygraceelson@uiowa.edu.

This is an Open Access article distributed under the terms of the Creative Commons Attribution 3.0 Unported License (http://creativecommons.org/licenses/by/3.0), which permits unrestricted use, distribution, and reproduction in any medium, provided the original work is properly cited 
Alternatively, some suggest that delayed and/or written feedback may be preferable in certain situations. Delayed feedback appears to support better transfer of learning because it affords learners the time needed to independently process their experience before receiving feedback from an evaluator. ${ }^{3}$ This approach may be particularly beneficial in situations involving more difficult or complex items that require greater degrees of processing. ${ }^{4} \quad$ Further, written feedback may have advantages over face-to-face feedback because written feedback is likely to be perceived as less threatening and more objective. ${ }^{5}$

Delayed, web-based feedback is also attractive from an operational standpoint. The availability of webbased video-recording and documentation systems allows a faculty member to observe student performance in a clinical exam and provide feedback when it is convenient for the faculty member and without interfering with clinical obligations. This is an important consideration given the significant logistical issues encountered when administering structured clinical exams and scheduling faculty observers to provide immediate faceto-face feedback to students.

Web-based systems also have logistical advantages for students. It enables the students to augment feedback received by reviewing the video-recording of their own clinical exam at a time of their convenience. We hypothesized that today's mediasavvy students might find web-based written feedback at least as effective, and perhaps more effective, than inperson immediate feedback.

\section{Methods}

This study was reviewed and approved by the University of lowa Institutional Review Board. The PBA consisted of three fifteen-minute problem-focused interactions with standardized patients (SPs). One of these three cases was selected for faculty observation for the course of the study. Students were assigned to immediate face-to-face or delayed, written on-line feedback. The original intent was to systematically assign half the students to each group within each block but was not possible due to faculty physician availability; the two groups were kept even by adjusting the number in each group on an every other block basis throughout the year. The same group of nine trained faculty observers provided feedback on the same case throughout the course of the study, with all performing approximately equivalent numbers of face-to-face and delayed on-line sessions.

In the case of immediate feedback, each student was observed in real time via video camera and the faculty member provided approximately ten minutes of face-toface feedback to the observed students immediately following the case. In the case of delayed feedback, the video recording of the case was observed by a faculty member within five working days and written feedback provided via a webbased form. After all reviews were 
completed, the students were given access to the written faculty comments. Usually the students had access to the web-based written faculty comments seven or eight working days after the PBA, but there were on occasion technical problems that resulted in the comments posted as much as twelve working days after the PBA.

In addition to the faculty feedback on the selected case, all students also received web-based written feedback from the SPs on all three cases in which they participated, as well as the ratings of the SPs on all three cases using a standardized checklist unique to the case. The SP ratings and comments were released within twenty-four hours of completion of the PBA. All students also were provided access to their individual video recordings for all three cases. The video-recordings were released following completion of all faculty feedback. The rationale for delaying release of videos is because the literature suggests a video review is more effective for the student in the presence of performance feedback. ${ }^{6}$

One week after release of all videos and web-based faculty feedback, all students participating in the PBA were invited to participate in an anonymous web-based survey. The survey was designed to determine if significant differences existed between the two groups in ratings of commonly accepted characteristics of effective feedback. The survey was piloted with 37 students prior to initiation of the study. Following the pilot, we realized that very few students were choosing to view their video recording. We therefore added two questions to gather qualitative data regarding students' perception of reviewing their videos. We also added a question which asked students in each group if they would have preferred to be in the other group, i.e., if a student that received delayed web-based feedback would have preferred faceto-face feedback and vice-versa. The survey used in this study is shown in the supplemental material. Survey results were not linked to any particular faculty member.

At the completion of the study, an independent samples t-test was used to determine if there were statistically significant differences between the two study groups. A $p$ value of $\leq 0.05$ was considered statistically significant. In addition, the qualitative data from the exploratory portion of the study was reviewed and summarized.

\section{Results}

This study surveyed 163 third year medical students at the University of lowa who participated in the Obstetrics and Gynecology PatientBased Assessment (PBA) over a one-year period (October 2009 October 2010). The demographic characteristics of this cohort were as follows: gender - 77 (47\%) female, $86(53 \%)$ male; race/ethnicity - 138 (85\%) White, 18 (11\%) Asian, 7 (4\%) African-American; mean age $=25.4$ years, std dev $=2.81 .95 \%$ of these students were between 22-29 years old, inclusive. All third year medical students have previously conducted 
several video recorded encounters with standardized patients with face-to-face and web-based feedback as part of earlier portions of the University of lowa medical school curriculum.

A total of 97 students $(59 \%)$ responded to the web-based survey. Of these students, 84 $(52 \%)$ responded to the questions about feedback quality, with a distribution of 40 respondents that received face-to-face feedback and 44 respondents that received delayed web-based feedback.

The quality of 11 feedback characteristics was rated on a 5-point scale with 5 indicating the highest quality. Table 1 displays the mean differences in ratings by feedback method. Face-toface feedback scored higher than web-based feedback on all 11 characteristics, and received statistically significantly higher ratings on 9 of the 11 variables

Only 9 of the 97 students (9.3\%) chose to view their video recording. Those who did view the recording tended to watch it alone. Common reasons for not reviewing the video were lack of time to do so, not liking to watch oneself on video, and thinking that it would not add to the feedback.
Table 1. Mean Student Ratings of Formative Feedback Characteristics by Method

\begin{tabular}{|l|l|l|}
\hline $\begin{array}{l}\text { The faculty feedback I } \\
\text { received: }\end{array}$ & Face-to-Face & $\begin{array}{l}\text { Web-based } \\
\text { Written } \\
\text { Mean (std err) }\end{array}$ \\
\hline Wean (std err) & $4.425(0.087)$ & $3.841^{* *}(0.121)$ \\
\hline Was nonthreatening & $4.300(0.130)$ & $4.045(0.112)$ \\
\hline $\begin{array}{l}\text { Was objective ( not } \\
\text { biased) }\end{array}$ & $4.275(0.101)$ & $4.045(0.102)$ \\
\hline $\begin{array}{l}\text { Focused on important } \\
\text { issues }\end{array}$ & $4.300(0.096)$ & $3.907^{*}(0.136)$ \\
\hline Had practical application & $4.350(0.092)$ & $3.907^{* *}(0.132)$ \\
\hline $\begin{array}{l}\text { Mentioned specific } \\
\text { behaviors }\end{array}$ & $4.400(0.106)$ & $3.837^{* *}(0.148)$ \\
\hline $\begin{array}{l}\text { Was in an amount I could } \\
\text { absorb at the time }\end{array}$ & $4.425(0.869)$ & $4.046^{*}(0.124)$ \\
\hline $\begin{array}{l}\text { Identified strengths in my } \\
\text { PBA performance }\end{array}$ & $4.200(0.148)$ & $3.714^{*}(0.150)$ \\
\hline $\begin{array}{l}\text { Addressed weaknesses in } \\
\text { my PBA performance }\end{array}$ & $4.300(0.102)$ & $3.860^{* *}(0.122)$ \\
\hline $\begin{array}{l}\text { Will be helpful in my } \\
\text { future PBAs }\end{array}$ & $4.026(0.138)$ & $3.465^{* *}(0.161)$ \\
\hline $\begin{array}{l}\text { Will be beneficial in my } \\
\text { future care of patients }\end{array}$ & $4.184(0.106)$ & $3.488^{* *}(0.174)$ \\
\hline
\end{tabular}

$* p \leq 0.05$ as compared to the face-to-face mean. $* * \mathrm{p} \leq 0.01$ as compared the face-to-face mean.
The survey also included a direct question regarding student preference for mode of feedback. Of the students who received webbased feedback, $74 \%$ indicated they would have preferred face-to-face feedback. In contrast, only $17 \%$ of the students who received face-toface feedback indicated they would have preferred web-based written feedback. These responses are consistent with the quantitative analysis above. 


\section{Discussion}

Our results indicate that the vast majority of third year medical students found face-to-face feedback on the PBA to be of higher quality and preferred it over written webbased feedback. Qualitative comments which the students provided in the survey indicate that the preference for face-to-face feedback stems from the two-way nature of the interaction. Students wanted to discuss, and ask clarifying questions about, faculty members' comments. A standard suggestion for faculty observers is to begin the feedback session by asking the student how s/he feels the encounter went ("ask, tell, ask"). The faculty member can then use the student's self-evaluation as a starting point for feedback. Further studies might explore incorporation of more interactive web-based elements that would allow a two-way exchange between learner and observer.

Only a small percentage of the students chose to view their video recording. Video review in conjunction with formative feedback is a powerful educational tool in developing general communication skills as well as more specific clinical skills. ${ }^{3}$ Others have previously noted that medical students do not enjoy watching themselves on video because they are highly self-critical. ${ }^{7}$ For example, the students can become overwhelmed by their errors in an encounter with a patient, and their negative self-assessment can be damaging. ${ }^{3}$
There are several limitations to consider when interpreting the results of our study. First, we studied only two possible configurations for feedback. Our study compared immediate, face-toface feedback with delayed, webbased feedback. We did not study delayed, face-to-face feedback as the PBA is completed on the penultimate day of the clerkship and the students would be on other clerkships a week later.

There were many technological issues that occurred in the course of our study, most of which involved delays in distribution of written faculty feedback to students. Such delays may have negatively affected the results from the web-based feedback group, but we considered these as the frequent consequence of using these technologies.

The focus of our study was on student perceptions of the formative feedback and did not measure its impact on student learning or subsequent clinical behavior. Furthermore, our survey instrument for assessing student perceptions of feedback, although pilot-tested extensively at the University of lowa, was developed specifically for the current study and consequently has not been widely tested. Lastly, since our study is based on one institution's students in one type of Objective Structured Clinical Exam (OSCE), whether this preference would generalize to medical students at other institutions and/or with other OSCEs remains unclear. 
In summary, our study found that our medical students prefer immediate, face-to-face faculty feedback following a patient assessment compared to delayed, web-based feedback. Our qualitative data suggest that one of the key reasons for the preference for face-to-face feedback is the two-way nature of the exchange. However, further studies are needed in a wider variety of OSCEs and environments to evaluate whether interactive webbased approaches that provide a two-way conversation between the learner and faculty observer (perhaps incorporating learner selfevaluation), might concomitantly meet the learner's needs and allow for flexibility for preceptor clinicians.

\section{References}

1. Hodder RV, Rivington RN, Calcutt LE, Hart IR. The effectiveness of immediate feedback during the objective structured clinical examination. Med Educ. 1989 Mar;23(2):184-8.
2. Black NM, Harden RM. Providing feedback to students on clinical skills by using the Objective Structured Clinical Examination. Med Educ. 1986 Jan;20(1):48-52.

3. Shute VJ. Focus on formative feedback. Rev Educ Res. 2008 Mar:78(1):153-189.

4. Hattie J, Timperley H.The power of feedback. Rev Educ Res. 2007 Mar:77(1):81-112.

5. Beckman HB, Frankel RM. The use of videotape in internal medicine training. J Gen Intern Med. 1994 Sep;9(9):517-21.

6. Nilsen S, Baerheim A. Feedback on video recorded consultations in medical teaching: why students loathe and love it - a focus-group based qualitative study. BMC Med Educ. 2005 Jul 19;5:28.

7. Srinivasan M, Hauer KE, DerMartirosian C, Wilkes M, Gesundheit N. Does feedback matter? Practice-based learning for medical students after a multiinstitutional clinical performance examination. Med Educ. 2007 Sep;41(9):857-65. 